\title{
THE CROWN DIAMETER ESTIMATION FROM FIXED WING TYPE OF UAV IMAGERY
}

\author{
A. Grznárová ${ }^{1 *}$, M. Mokroš ${ }^{1,2}$, P. Surový ${ }^{2}$, M. Slavík ${ }^{2}$, M. Pondelík ${ }^{1}$, J. Merganič ${ }^{3}$ \\ ${ }^{1}$ Department of Forest Management and Geodesy, Faculty of Forestry, Technical University in Zvolen, 96053 Zvolen, Slovakia, \\ alzbeta.grznarova@tuzvo.sk; xpondelik@is.tuzvo.sk \\ ${ }^{2}$ Faculty of Forestry and Wood Sciences, Czech University of Life Sciences Prague, 16500 Praha 6-Suchdol, Czech Republic, \\ mokros@fld.czu.cz; surovy@fld.czu.cz; mslavik@fld.czu.cz \\ ${ }^{3}$ Department of Forest Harvesting, Logistics and Ameliorations, Faculty of Forestry, Technical University in Zvolen, 96053 Zvolen, \\ Slovakia, merganic@tuzvo.sk
}

KEY WORDS: Unmanned aerial vehicle (UAV), crown diameter, Inverse Watershed Segmentation (IWS), forestry, tree species

\begin{abstract}
:
The forest inventory is an important instrument for sustainable forest management. Canopy Height Model (CHM) and Digital Surface Model (DSM) created from high-resolution UAV (unmanned aerial vehicle) imagery provide possibility to determine tree crown diameters for the whole stand at fast. The goal of this paper is to identify the influence of tree species on the accuracy of estimation of crown diameter from high-resolution UAV imagery. In Plot 1 with coniferous tree species we identified 21 trees from total of 22 trees that leads to a detection rate of $95 \%$. In Plot 1 with deciduous trees species we identified 24 trees from total 34 trees that leads to a detection rate of $71 \%$. The RMSE errors calculated between the reference crown diameters and estimated crown diameters by IWS on Plot 1 and Plot 2 were calculated as $0.80 \mathrm{~m}(\mathrm{RMSE} \%=21.85)$ and $1.89 \mathrm{~m}(\mathrm{RMSE} \%=21.54)$, respectively. The results didn't show the significant influence of tree species on the accuracy of estimation of crown diameter from high-resolution UAV imagery. However, result showed the significant influence of tree species on the detection number trees on the plot. The detection of number trees on the plot by method Inverese Watersed Segmentation in software ArcGis is higher for coniferous tree species. It is mainly due to the overlapping crowns.
\end{abstract}

\section{INTRODUCTION}

The forest inventory is an important instrument for sustainable forest management. The purpose of forest inventories is to estimate means and totals for measures of forest characteristic over a defined area. Such characteristic include the volume of the growing stock, the area of certain type of forest and nowadays also measures concerned with forest biodiversity, e.g. the volume of dead wood or vegetation (Kangas and Maltamo, 2006). The data acquisition during forest inventory is time- and costdemanding. Unmanned aerial vehicle (UAV) in combination with digital photogrammetry provides possibilities for effective data acquisition.

Several studies have focused on usage of UAVs and digital photogrammetry for forest inventory. Fritz et al., (2013) used UAV imagery to automatically detect and reconstruct individual trees. Study Lisein et al. (2013) aimed at determining how dominant height at stand level and individual tree height of an uneven-aged broad- leaved forest dominated. Puliti et al. (2015) used three-dimensional (3D) variables derived from UAV imagery in combination with ground reference data to fit linear models for Lorey's mean height, dominant height, stem number, basal area, and stem volume. Other studies have dealt with tree species classification. For example, study Michez et al. (2016) proposed a methodological framework to classification of riparian forest species and health condition using multi-temporal and hyperspatial imagery from UAV. Study Cao et al. (2018) investigated the capability of UAV hyperspectral images for distinguishing and mapping mangrove species using objectbased approaches. Another study demonstrated how UAV

\footnotetext{
* Corresponding author
}

images can be used for quantifying spatial gap patterns in forest related to the spatio-temporal dynamics of forests.

Crown diameter is one of tree characteristic that are collected during forest inventory. It is significantly important because it strongly correlates with other tree dimensions used to estimate the volume of the growing stock. Currently, crown diameter of each single individual tree in forest stand is measured separately by terrestrial methods. Canopy Height Model (CHM) and Digital Surface Model (DSM) created from high-resolution UAV imagery provide possibility to determine tree crown diameters for the whole stand at fast. Several studies used UAV photogrammetry to determine tree crown diameters. They used for example object-based image analysis technique (OBIA) (Guerra-Hernandez et al., 2016; Johansen et al., 2018; TorresSánchez et al., 2015) or algorithm Inverse Watershed Segmentation (IWS) (Panagiotidis et al., 2017). The technique OBIA is based on merging similar pixels to homogeneous segments. Individual pixels are merging with neighbouring ones based on by the following parameters: shape, scale, compactness and colour scale (González-Ferreiro et al., 2013). The algorithm IWS is based on inverting the CHM so the model is turned upside down the peaks become depressions. When the raster surface is configured as a depression model, watershed segmentation can then be performed to delineate basins (Edson and Wing, 2011). The technique OBIA were applicated in software eCognition, while the algorithm IWS were applicated in software ArcGIS.

For UAV imagery acquisition authors of studies used fixed-wing UAVs (Guerra-Hernandez et al., 2016; Shin et al., 2018) or rotary-wing UAVs (Patrick and Li, 2017; Yilmaz et al., 2017; Panagiotidis et al., 2017; Torres-Sánchez et al., 2015). UAV 
imagery were made by RGB camera (Díaz-Varela et al., 2015; Guerra-Hernandez et al., 2016; Panagiotidis et al., 2017; Patrick and $\mathrm{Li}, 2017$ ) or multispectral camera (Johansen et al., 2018; Torres-Sánchez et al., 2015; Shin et al., 2018). UAV imagery were post-processed mainly in the Pix4D software (Díaz-Varela et al., 2015; Guerra-Hernandez et al., 2016; Johansen et al., 2018; Shin et al., 2018) or Agisoft Photoscan (Panagiotidis et al., 2017; Patrick and Li, 2017; Torres-Sánchez et al., 2015; Yilmaz et al., 2017).

They focused on various segmentation techniques or on discontinuous and continuous canopy cropping systems. However, to our best knowledge the studies did not focus on comparison of the diameter accuracy among various tree species and most of the studies used rotary-wing types of UAV. Which serve great detail and accuracy. On the other hand, rotary-wing UAVs need more time to cover larger areas with comparison to fixed wing UAV.
The goal of this paper is to assess the accuracy of crown diameter estimation and to identify the influence of tree species on the accuracy of estimation of crown diameter from high-resolution UAV imagery using fixed wing eBee Plus RTK/PPK.

\section{MATERIAL AND METHODS}

\subsection{Study plots}

For purposes of the study, two research plots were established (Figure 1). They were located near Zvolen, Slovakia (48 37'41", $\mathrm{N}, 19^{\circ} 02^{\prime} 19^{\prime \prime}$ E). The distance between the plots was approximately $600 \mathrm{~m}$. Both plots were covered with forest stand with 0.9 stocking. Plot 1 had 22 trees with predominant Europeansilver fir (Abies alba Mill.) Plot 2 had 34 trees with mainly sessile oak (Quercus petraea (Matt.) Liebl.) and European beech (Fagus sylvatica L.). Both plots had circular shape with the area of 500 square meters.

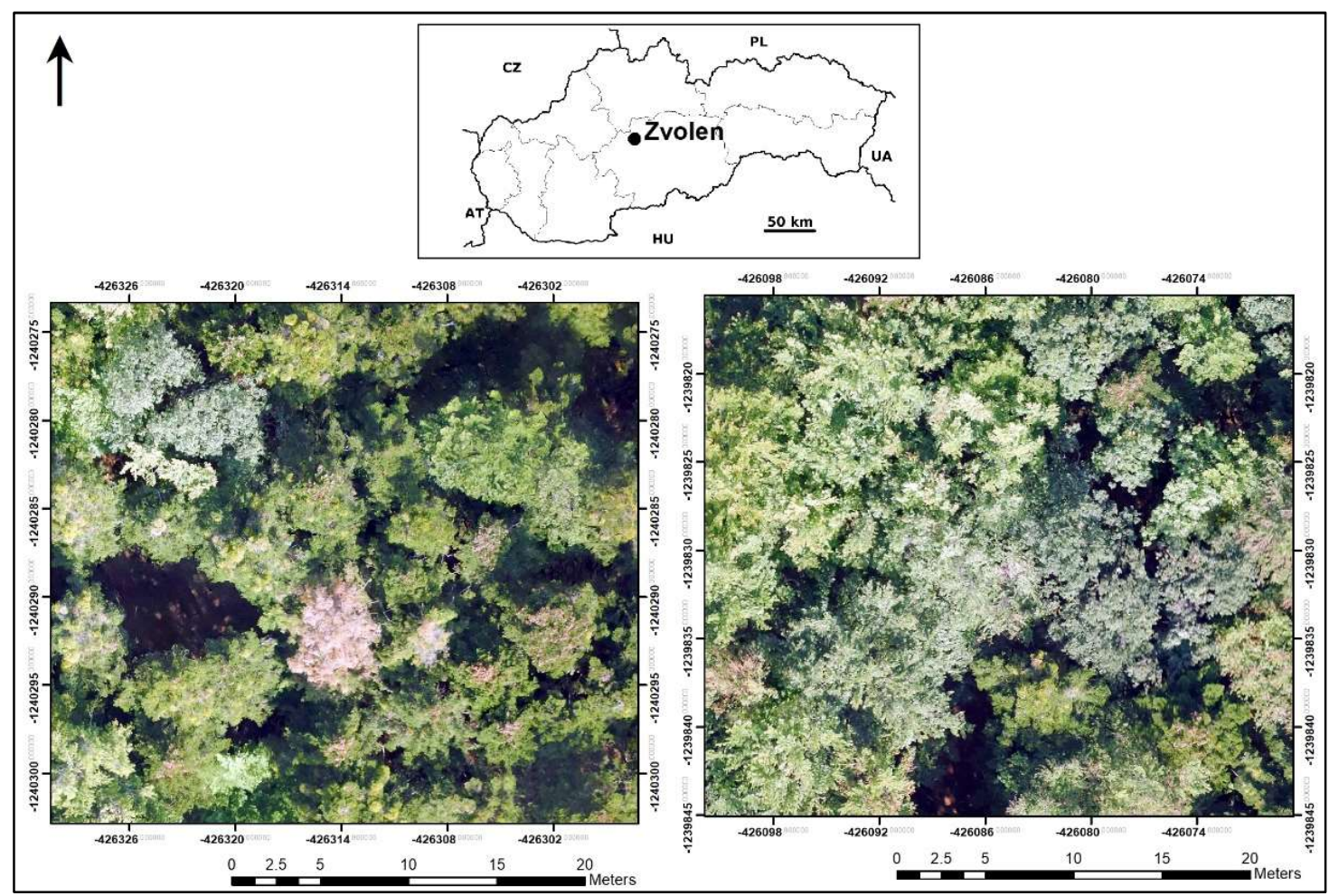

Figure 1. Location of research plots. The left is Plot1 and the right is Plot 2

\subsection{Field measurements}

The positions and crown projections of all trees on both plots were measured by FieldMap technology, consisting of digital compass, laser rangefinder and terrain computer. The positions were measured using the azimuth-distance approach from the plot centre. The crown projections were measured by 4 border points of the crown's outline in east-west and north-south directions. The field measurements for both plots were collected in the same month as the aerial images acquisition was performed.

\subsection{Aerial images acquisition}

For imagery acquisition was used the UAV eBee Plus RTK/PPK (Figure 2) during the leaf-on conditions on both plots. This fixedwing UAV has wingspan of $110 \mathrm{~cm}$, weights $1,1 \mathrm{~kg}$, and can launch from hand. The camera, used for data acquisition, was SenseFly S.O.D.A. RGB, with an 18 MP resolution (5272 x 3648 pixels).

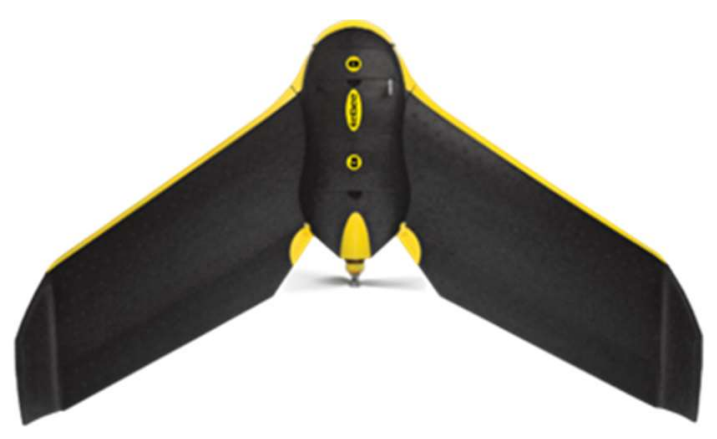

Figure 2. UAV eBee Plus RTK/PPK 
It was used a 1-inch RGB sensor and fixed focal length 10,6 mm. GNSS receiver used in the UAV configuration was the Septentrio AsteRx-m UAS. The flights were planned and processed in the eMotion 3 software. Planed image overlaps were 90x60\%, GSD between one and two centimetres. This resulted into the flight height of approximately $70 \mathrm{~m}$ AGL. Each of the flight lasted approximately 13 minutes at a flight speed of $10 \mathrm{~m} / \mathrm{s}$.

\subsection{Processing of photogrammetric data}

The UAV images were reconstructed by algorithm Structure from Motion and Multiview Stereopsis technique in the Agisoft Photoscan 1.4 software (Agisoft LCC, St. Petersburg, Russia). The standardly used workflow was applied. All images were geotagged using positions from postprocessed GNSS solution. Images were then aligned with Accuracy set to High and Pair Preselection set to Reference. Following steps included generation of dense clouds with Quality set to High and Depth filtering set to Mild. Finally, Digital surface model (DSM) and orthophotomosaic of both research plots were created from dense point cloud (Figure 3).
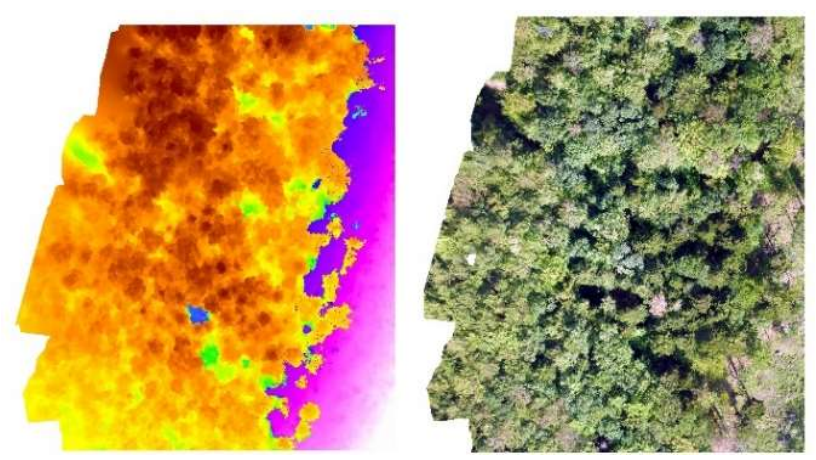

Figure 3. Inputs of software Agisoft Photoscan - DSM and ortophotomosaic from Plot 1

\subsection{Estimation of Canopy Parameters}

Individual tree crowns were delineated with using of Inverse Watershed Segmentation method in the environment of ArcGIS Desktop 1.4 software (ESRI). This methodology was proposed by Panagiotidis et al, (2017). As the input data were used DSM and orthophotomosaic. The tools Flow Direction and Basin was using on the inverse DSM. The original DSM were relocated to the Boolean raster and were multiplied by the result of the Basin tool by class 1 (including trees from the lowest to the highest tree) to remove large gaps between tree crowns. In other step, the raster displaying the edges of crowns was converted to polygons by the tool Raster to Polygon. However, a several small numbers of polygons belonged to one crown, so it was necessary to eliminate their number by several times using the Eliminate tool to correspond with the underlying orthophotomosaic (Figure 4). In the next step, crown polygons were converted to lines and lines were converted to points with using of tool Feature to Point. Finally, the distances points lying on the edge lines of tree crowns and centres of crowns were calculated with using of the tool Distance to points (Panagiotidis et al., 2017). The results of this workflow were average crown diameters of single individual trees on both research plots.

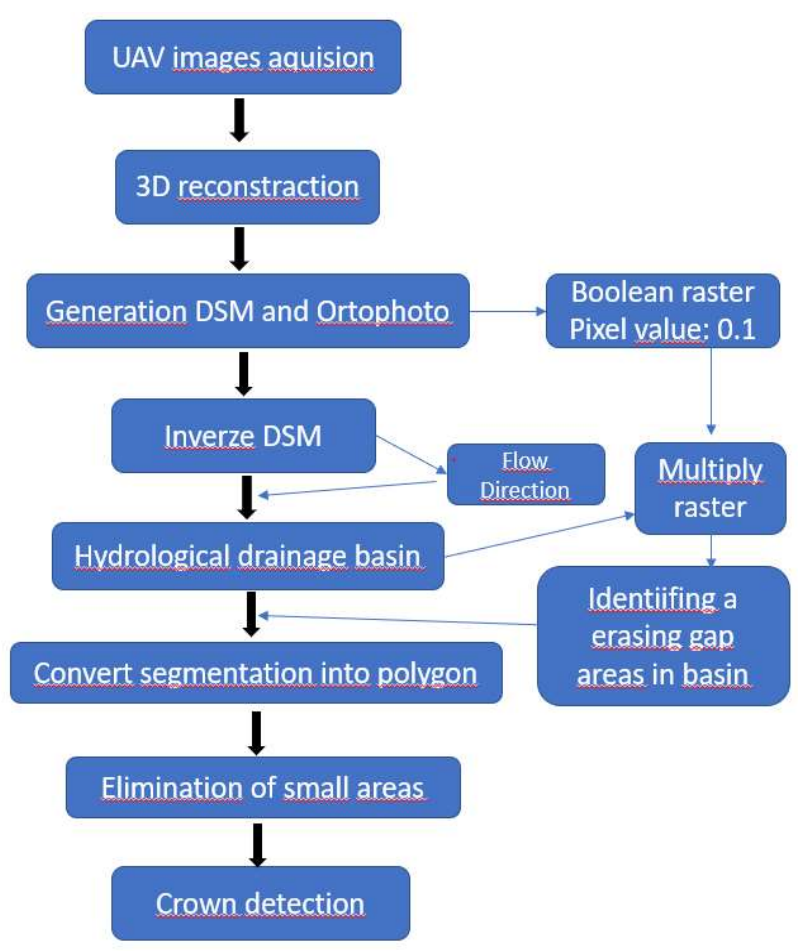

Figure 4. Scheme of crown detection (Panagiotidis et al., 2017) - edited

\section{RESULTS}

We compared estimated crown diameters with reference crowns diameter that were obtained by terrestrial measurements. We calculated differences and Root Mean Square Error (RMSE). In Plot 1 with coniferous tree species we identified 21 trees from total of 22 trees that leads to a detection rate of $95 \%$ (Figure 5). In Plot 1 with deciduous trees species we identified 24 trees from total 34 trees that leads to a detection rate of $71 \%$. The RMSE errors calculated between the reference crown diameters and estimated crown diameters by IWS on Plot 1and Plot 2 were calculated as $0.80 \mathrm{~m}(\mathrm{RMSE} \%=21.85)$ and $1.89 \mathrm{~m}(\mathrm{RMSE} \%=$ 21.54), respectively (Table 1).

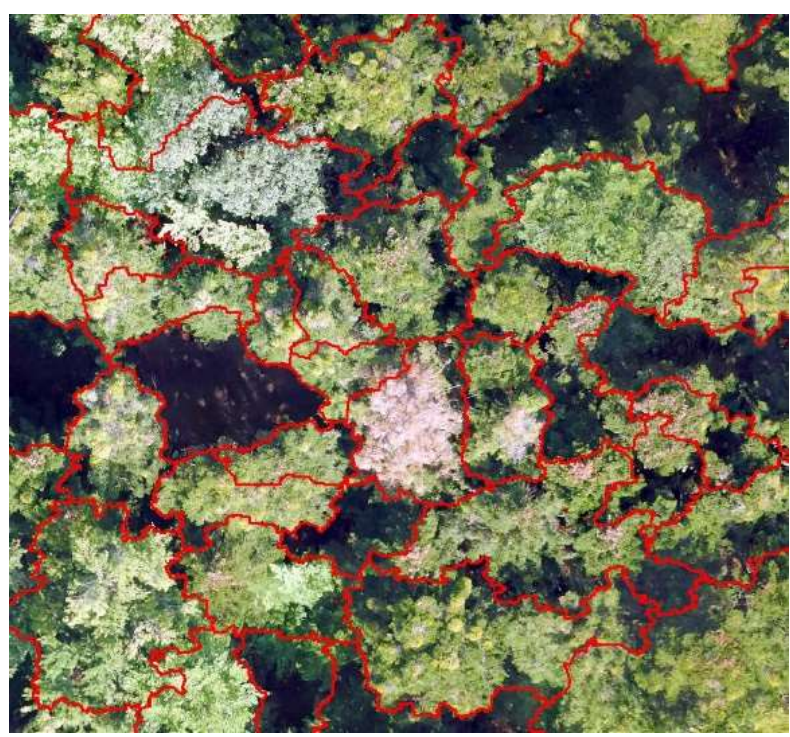

Figure 5. Polygon of tree crowns (Plot1) 


\begin{tabular}{|l|c|c|c|c|}
\hline $\begin{array}{l}\text { Plot } \\
\text { (species) }\end{array}$ & $\begin{array}{l}\text { Number of } \\
\text { detected / } \\
\text { total trees }\end{array}$ & $\begin{array}{l}\text { Detection } \\
\text { rate }\end{array}$ & $\begin{array}{l}\text { RMSE } \\
(\mathrm{m})\end{array}$ & RMSE\% \\
\hline $\begin{array}{l}\text { Plot } \\
\text { (JD) }\end{array}$ & $21 / 22$ & $95 \%$ & 0,80 & 21,85 \\
\hline $\begin{array}{l}\text { Plot } \\
\text { (DB) }\end{array}$ & $24 / 34$ & $71 \%$ & 1,89 & 21,54 \\
\hline
\end{tabular}

Table 1. Statistics of the measured and estimated crown diameters

\section{DISCUSSION}

Our study focused on estimation of crown diameter by fixedwing UAV in forest stands with dense canopy. There are some previous studies used the same type UAV on estimation of the crown. Study Shin et al. (2018) dealt with Ponderosa Pine Stand and achieved RMSE $0.88 \mathrm{~m}$ for crown diameter. We achieved similar accuracy (RMSE $0.80 \mathrm{~m}$ ) on Plot 1 with conifer tree species and with only partially overlapped crowns. Other study Guerra-Hernandez et al. (2016) used fixed wing UAV eBee to estimate tree variables and achieved RMSE $0.66 \mathrm{~m}$ (rRMSE $6.14 \%$ ). It is important to note that object of this study was Pinus pinea plantation on flat terrain with sparsely distributed trees.

Other studies were focused on estimation of crown diameter used rotary-wings UAV (Johansen et al., 2018; Patrick and Li, 2017; Panagiotidis et al., 2017; Yilmaz et al., 2017). Study Johansen et al., (2018) were focused on to establish the response of pruning in an orchard of lychee trees and used 3DR Solo cadrocopter and a Parrot Sequoia multi-spectral sensor. For crown diameter they achieved RMSE 0.26 m. Study Patrick and Li et al. (2017) researched the possibilities and accuracy of the low-cost unmanned aerial vehicle DJI Phantom 3 to determine the morphological characteristics of blueberries with discontinuous canopy. For crown diameter they achieved RMSE $5.57 \mathrm{~cm}$. Study Panagiotidis et al. (2017) used DJI S800 UAV platform and achieved RMSE $0.82 \mathrm{~m}$ and $1.04 \mathrm{~m}$ rRMSE $14.29 \%$ and $18.56 \%$. Study Yilmaz et al., (2017) used DJI Phantom 3 and were focused on comparation two various segmentation techniques Both the MR and RG segmentation algorithms detected 57 of them correctly, which leads to a detection accuracy of $90 \%$ for both algorithms. The RMS errors calculated between the reference crown diameters and MR and RG segmentation-derived crown diameters were calculated as $1.59 \mathrm{~m}$ and $1.76 \mathrm{~m}$, respectively.

Advantage of fixed-wing type of UAV compared to the rotarywing type is higher range. Disadvantage is impossibility to create enough quality DTM from the point cloud obtained from UAV images to estimate tree heights in forest stands with dense canopy. The solution is a combination UAV photogrammetry with airborne laser scanning (Jensen et al., 2016; Goldbergs et al., 2018). Aerial laser scanning provides data with high accuracy and quality. However, the data is poorly detailed and costly to collect. Therefore, aerial laser scanning is not suitable for detailed and regular monitoring in a short time period. On the other hand, UAS provides low cost, high spatial and temporal resolution data (Goodbody et al., 2017). Other alternative is usage of UAV-LiDAR (Sankey at al., 2017; Wallace et al., 2016).

\section{CONCLUSION}

The results did not show the significant influence of tree species on the accuracy of estimation of crown diameter from highresolution UAV imagery. However, results showed the significant influence of tree species on the detection number trees on the plot. The detection of number trees on the plot by method Inverese Watersed Segmentation in software Arcgis is higher for coniferous tree species. It is mainly due to the overlapping crowns.

In further research we will validate our results on the other plots with various tree species. Further, we will focus to identify the influence of vegetation season and impact of flight altitude on the estimation accuracy of crown diameter from high-resolution UAV imagery.

\section{ACKNOWLEDGEMENTS}

This research was funded by the Slovak Research and Development Agency through grant No. APVV-15-0714 ("Mitigation of climate change risk by optimization of forest harvesting scheduling"), and by grants No. CZ.02.1.01/0.0/0.0/16_019/0000803 ("Advanced research supporting the forestry and wood-processing sector's adaptation to global change and the 4th industrial revolution") financed by OP RDE.

We acknowledge the support of The ISPRS Foundation (TIF) in the form of TIF Travel Grants, which enabled us to attend the conference ISPRS Geospatial Week 2019.

\section{REFERENCES}

Cao, J., Leng, W., Liu, K., Liu, L., He, Z. and Zhu, Y., 2018. Object-based mangrove species classification using unmanned aerial vehicle hyperspectral images and digital surface models. Remote Sens, 10(1), 89. doi.org/10.3390/rs10010089

Díaz-Varela, R., Rosa, R., León, L., Zarco-Tejada, P., 2015. High-Resolution Airborne UAV Imagery to Assess Olive Tree Crown Parameters Using 3D Photo Reconstruction: Application in Breeding Trials. Remote Sensing, 7(4), 4213-4232. doi.org/10.3390/rs70404213

Edson, C. and Wing, M.G., 2011. Airborne light detection and ranging (LiDAR) for individual tree stem location, height, and biomass measurements. Remote Sens, 3(11), 2494-2528. doi: $10.3390 / \mathrm{rs} 3112494$

Fritz, A., Kattenborn, T. and Koch, B., 2013. UAV-based photogrammetric point clouds - tree stem mapping in open stands in comparison to terrestrial laser scanner point clouds. ISPRS Ann. Photogramm. Remote Sens. Spatial Inf. Sci., XL-1/W2 (UAV-g2013), 141-146. doi.org/10.5194/isprsarchives-XL-1W2-141-2013

Getzin, S., Nuske, R. and Wiegand, K., 2014. Using unmanned aerial vehicles (UAV) to quantify spatial gap patterns in forests. Remote Sens, 6(8), 6988-7004. doi:10.3390/rs6086988

Goldbergs, G., Maier, S., Levick, S. and Edwards, A., 2018. Efficiency of individual tree detection approaches based on lightweight and low-cost UAS imagery in Australian Savannas. Remote Sens., 10(2), 161. doi.org/10.3390/rs10020161.

González-Ferreiro, E., Diéguez-Aranda, U., Barreiro-Fernández, L., Buján, S., Barbosa, M., Suárez, JC., Miranda, D., 2013. A mixed pixel-and region-based approach for using airborne laser scanning data for individual tree crown delineation in Pinus radiata D. Don plantations. International Journal of Remote Sensing, 34(21), 671-7690. doi.org/10.1080/01431161. 2013.823523 
Goodbody, T.R., Coops, N.C., Marshall, P.L., Tompalski, P., Crawford, P., 2017. Unmanned aerial systems for precision forest inventory purposes: A review and case study. The Forestry Chronicle, 93(1), 71-81. doi.org/10.5558/tfc2017-012

Guerra-Hernandez, J., Gonzalez-Ferreiro, E., Sarmento, A., Silva, J., Nunes, A., Correia, A.C., Fontes, L., Tomé, M., DiazVarela, R., 2016. Short Communication. Using high resolution UAV imagery to estimate tree variables in Pinus pinea plantation in Portugal. Forest Systems, 25(2). doi.org/10.5424/fs/201625208895

Jensen, J., Mathews, A. 2016. Assessment of image-based point cloud products to generate a bare earth surface and estimate canopy heights in a woodland ecosystem. Remote Sens., (1), 50. doi.org/10.3390/rs8010050

Johansen, K., Raharjo, T., McCabe, M.F., 2018. Using multispectral UAV imagery to extract tree crop structural properties and assess pruning effects. Remote Sens., 8(1), 50. doi.org/10.3390/rs8010050

Kangas, A. and Maltamo, M. eds., 2006. Forest inventory: methodology and applications (Vol. 10). Springer Science \& Business Media. Dordrecht, 3-11.

Lisein, J., Pierrot-Deseilligny, M., Bonnet, S. and Lejeune, P., 2013. A photogrammetric workflow for the creation of a forest canopy height model from small unmanned aerial system imagery. Forests, 4(4), 922-944. doi.org/10.3390/f4040922

Michez, A., Piégay, H., Lisein, J., Claessens, H. and Lejeune, P., 2016. Classification of riparian forest species and health condition using multi-temporal and hyperspatial imagery from unmanned aerial system. Environmental monitoring and assessment, 188 (3): 1-19. doi.10.1007/s10661-015-4996-2.

Panagiotidis, D., Abdollahnejad, A., Surový, P., Chiteculo, V., 2017. Determining tree height and crown diameter from highresolution UAV imagery. International Journal of Remote
Sensing,

38 ,

$2392-2410$

doi.org/10.1080/01431161.2016.1264028

Patrick, A. and Li, C., 2017. High throughput phenotyping of blueberry bush morphological traits using unmanned aerial systems. Remote Sens., 9(12), 1250. doi.org/10.3390/rs9121250

Puliti, S.; Ørka, H.O.; Gobakken, T.; Næsset, E., 2015. Inventory of Small Forest Areas Using an Unmanned Aerial System. Remote Sens., 7(8), 9632-9654. doi.org/10.3390/rs70809632

Sankey, T., Donager, J., McVay, J. and Sankey, J.B., 2017. UAV lidar and hyperspectral fusion for forest monitoring in the southwestern USA. Remote Sensing of Environment, 195, 30-43. doi.org/10.1016/j.rse.2017.04.007

Shin, P., Sankey, T., Moore, M., Thode, A., 2018. Evaluating Unmanned Aerial Vehicle Images for Estimating Forest Canopy Fuels in a Ponderosa Pine Stand. Remote Sens., 10(8), 1266. doi.org/10.3390/rs10081266

Torres-Sánchez, J., López-Granados, F., Serrano, N., Arquero, O., Peña, J., 2015. High- Throughput 3-D Monitoring of Agricultural-Tree Plantations with Unmanned Aerial Vehicle (UAV) Technology. PLoS ONE, 10(6). doi.org/10.1371/journal.pone.0130479

Wallace, L., Lucieer, A., Malenovský, Z., Turner, D. and Vopěnka, P., 2016. Assessment of forest structure using two UAV techniques: A comparison of airborne laser scanning and structure from motion (SfM) point clouds. Forests, 7(3), 62. doi.org/10.3390/f7030062

Yilmaz, V., Yilmaz, C.S., Tasci, L. And Gungor, O., 2017. Determination of Tree Crown Diameters with Segmentation of a UAS-Based Canopy Height Model. IPSI Bgd Transactions on Internet Research, 13(2),63-7. 